\title{
The dawn of neurosurgery in pre-conquest Mesoamerican territories
}

\author{
Graciela Zuccaro $^{1}$ (])
}

Received: 3 May 2017 / Accepted: 14 May 2017

(C) Springer-Verlag Berlin Heidelberg 2017

Today I would like to take you back in time....

In 1492, the Italian born navigator, Christopher Columbus, presented to the Spanish Queen Isabel the Catholic, a plan to cross the Atlantic Ocean on a westward route to reach India and China and to negotiate riches with the Asian continent. With the plan approved, Columbus set sail with his three ships: La Niña, La Pinta, and La Santa Maria. On October 12th, 1492, Columbus landed in the island of Guanahani in the archipelago of The Bahamas, which he baptized as San Salvador, where they were met by local, semi-naked inhabitants that he called "Indios", "Indians", believing that he had reached India (Fig. 1).

But in fact, Columbus had discovered the American continent.

What today is called Latin America, back then was a very vast yet heterogeneous territory inhabited by nomadic tribes with minimal group organization but with an echelon of political and social structures very comparable to the most developed European ones of the time.

The two predominant areas of prescientific development pertain to Mesoamerica: an area conformed by the central region of the American continent, which extended from the center of Mexico to present day Nicaragua, with its Mayan and Aztec Empires; and South America, whose major apogee was reached during the Incan Empire whose capital was in Cuzco, Peru yet extended westward into Ecuador, Bolivia,

Graciela Zuccaro

gnzuccaro@gmail.com

1 Buenos Aires, Argentina
Chile, and Northern Argentina, and the Jívaro Shuar in Ecuador (Fig. 2).

In both regions of Mesoamerica, there already existed rich cultures with their own symbolisms and theories, but these were eventually absorbed or destroyed by the aforementioned Indian empires and later on by European powers. But during the centuries following the establishment of the first agricultural settlements, (Fig. 3a, b) several social and cultural features evolved among Mesoamerican and South American societies, such as complex calendar and numeral system, (Fig. 4) rich and colorful mythological traditions, advanced astronomical knowledge (Fig. 5), and distinct architectural styles whose vestiges still remain (Fig 6).

The origins of pre-Columbian medicine date back to 1500 years before Christ. Health was measured with a hot/ cold polarity, and this balance affected the body and its relation to the cosmos. Everything that was masculine, celestial, or came from above was considered warm; on the contrary, all that was feminine came from below, and the underworld was considered cold. And disease had a multifactorial origin: it could be due to the punishment from the Gods, caused by another man's evil, or a stroke of fate destined from birth.

At the time, there was a persistent belief that medicine had a "magical" aspect to it: if supernatural forces caused disease, then in order to cure the disease, it was necessary to orchestrate against these evil influences whether they came from the stars/cosmos or from relegated faraway forces or from certain animals, such as the serpent that lived deep within the land and was considered to carry out the will of the dead.

The magician, wizard, or sorcerer was the expert who possessed the ability to communicate with superior beings, and to have influence upon them through prayer or threats in order to modify their adverse effect. Here emerged the infamous first "witch doctors" who observed the stars, fire, animal entrails in 
Fig. 1 Christopher Columbus meeting the "Indians"

Fig. 2 Depicts predominant areas of civilizations and of prescientific development

Fig. 3 a Aztec Farmers harvesting maize outside of Majea (Teotihuacán). b Mayan Stone Calendar
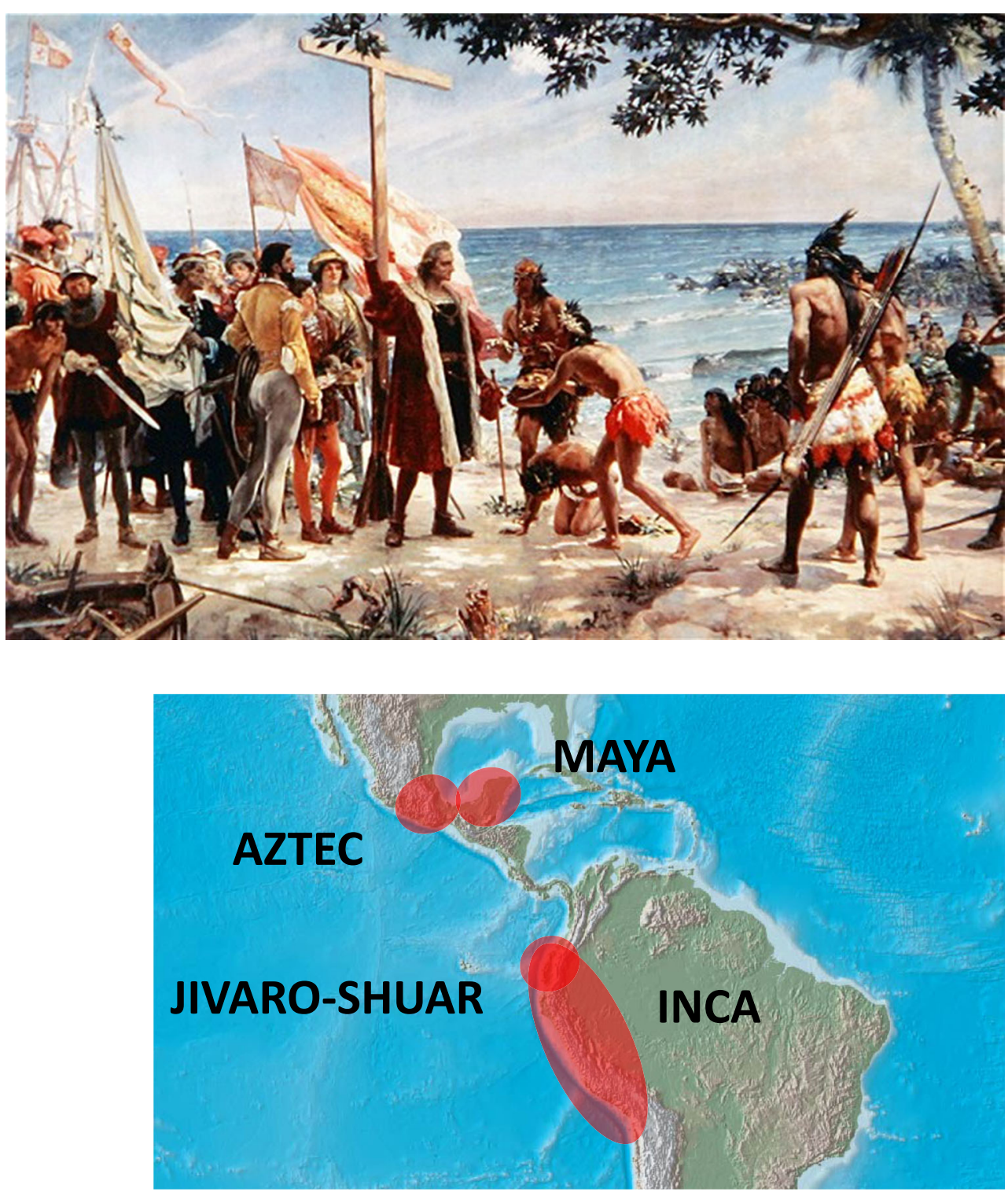

a

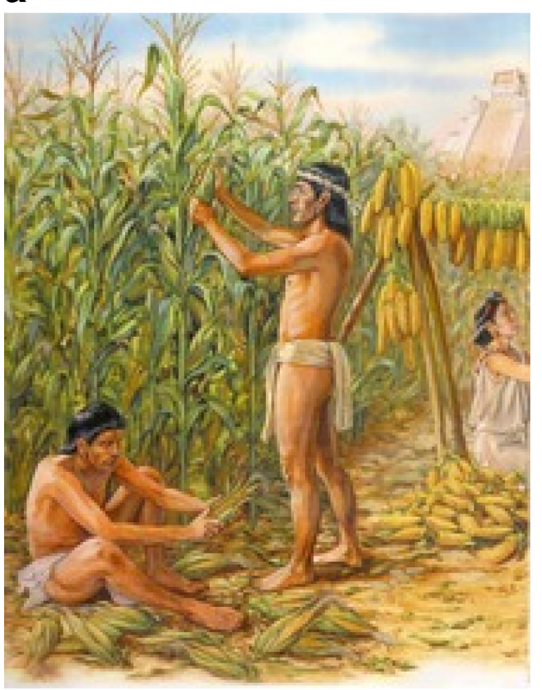

b

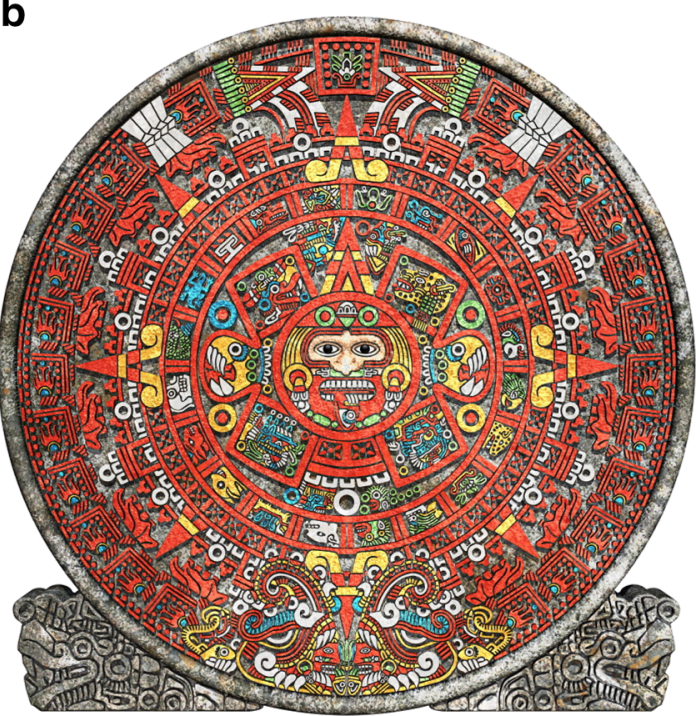




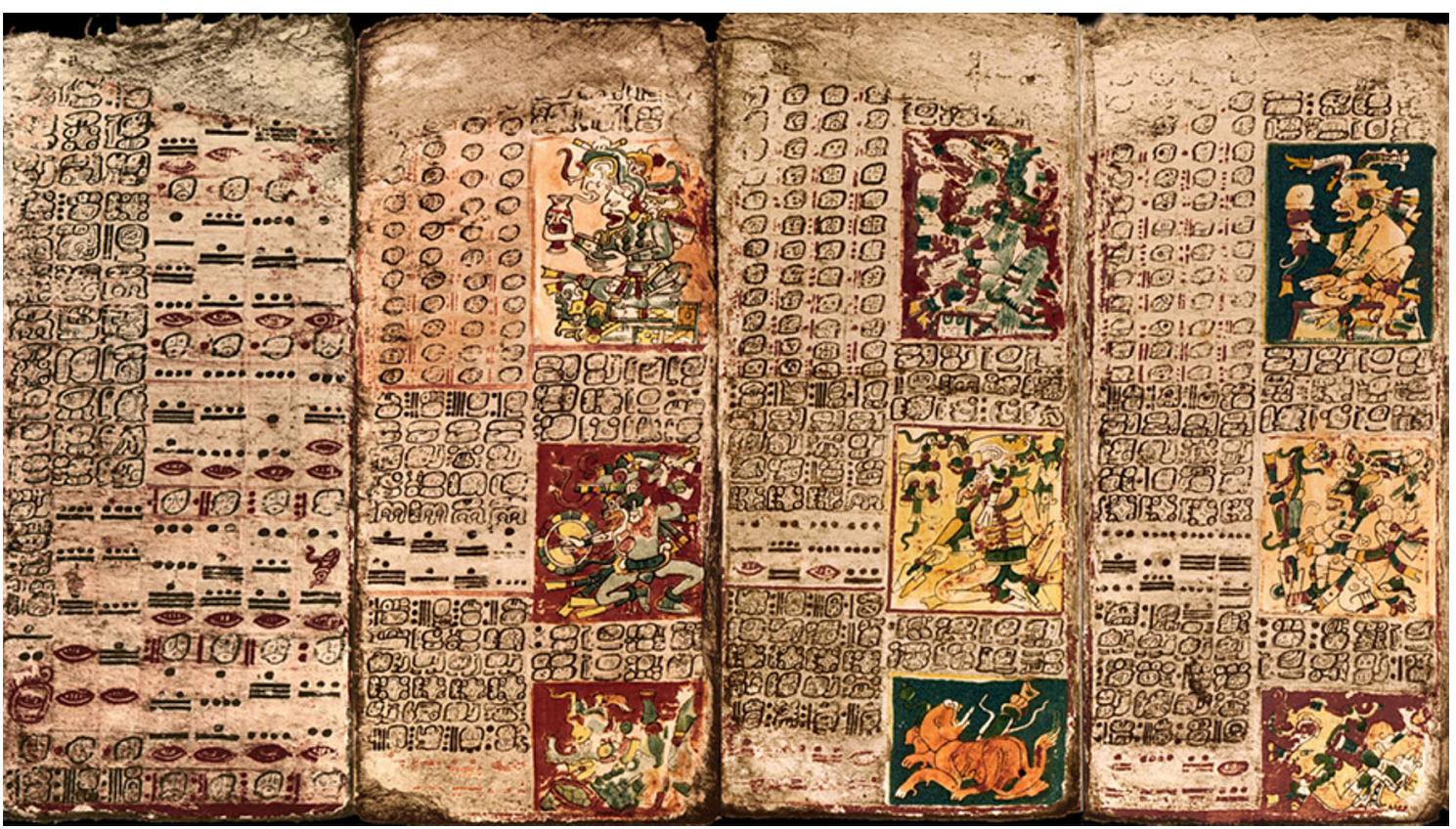

Fig. 4 Six sheets of the Dresden Codex from the pre-Columbian Maya civilization

order to predict the future and to cure diseases. Their power grew exponentially during times of disease epidemics and wars.

These doctors constituted a separate cast. They were prepped from childhood with special rituals and complicated initiations. They wore elaborate colorful garments decorated with precious jewels, animal feathers, and sacred amulets that bestowed upon them a mysterious aura of superiority over other men; (Fig. 7) and therefore, gave them the authority to practice their profession. They possessed an immense knowledge of the virtues of the plants used to prepare their potions and also of the variety of animal poisons. They were in charge of animal and human sacrifices, and of human decapitation. These topics shall be expanded upon later in this document.

The use of psychoactive substances was common in preColombian Mesoamerican societies. Hallucinogenic cactus, plants, and mushrooms that contained mescaline were used to induce altered states of consciousness in healing rituals and religious ceremonies.

The shaman, the intermediaries between the real and the supernatural worlds, were the only ones who knew the book

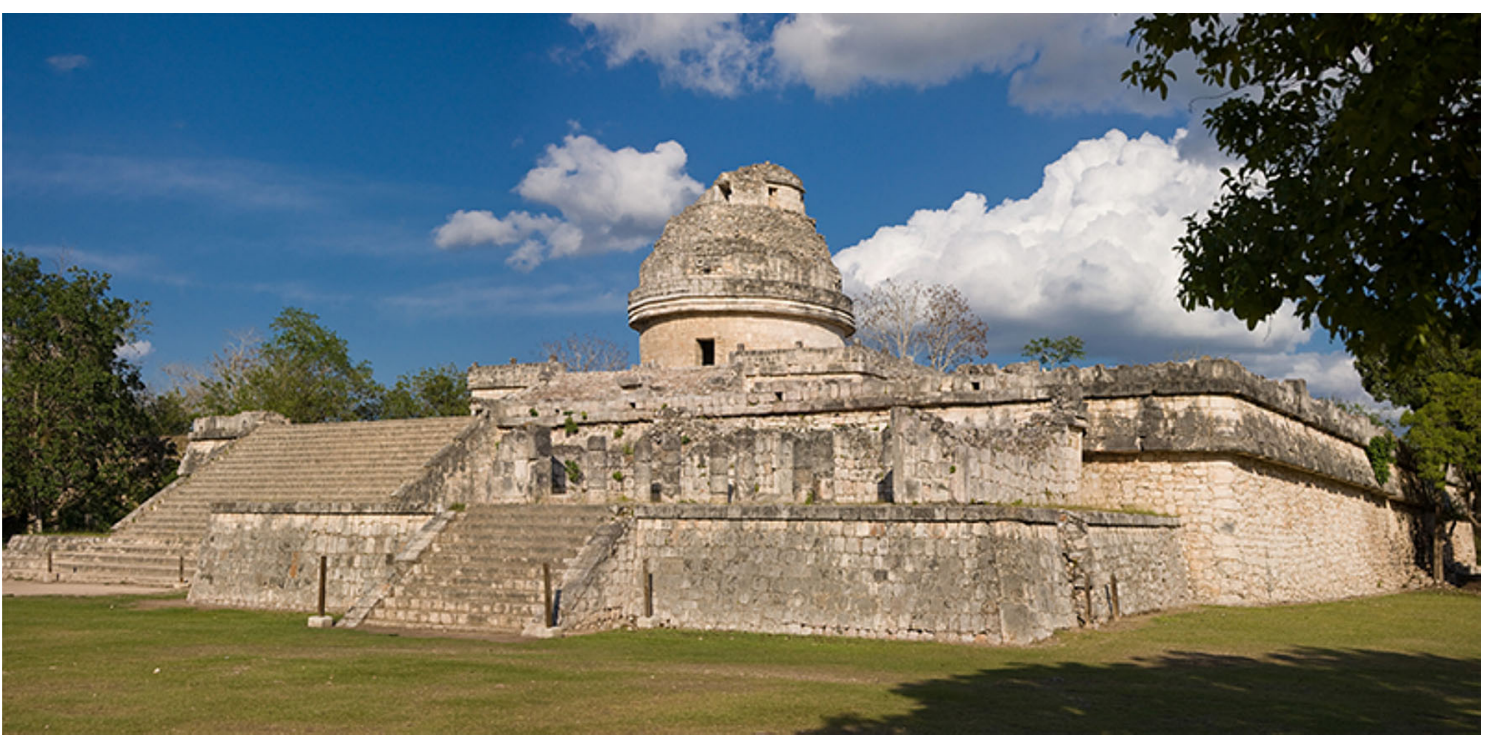

Fig. 5 Maya Astronomical Observatory Temple, known as "El Caracol", Chichen Itza, Mexico 
Fig. 6 Inca Civilization, Machu Picchu, Peru

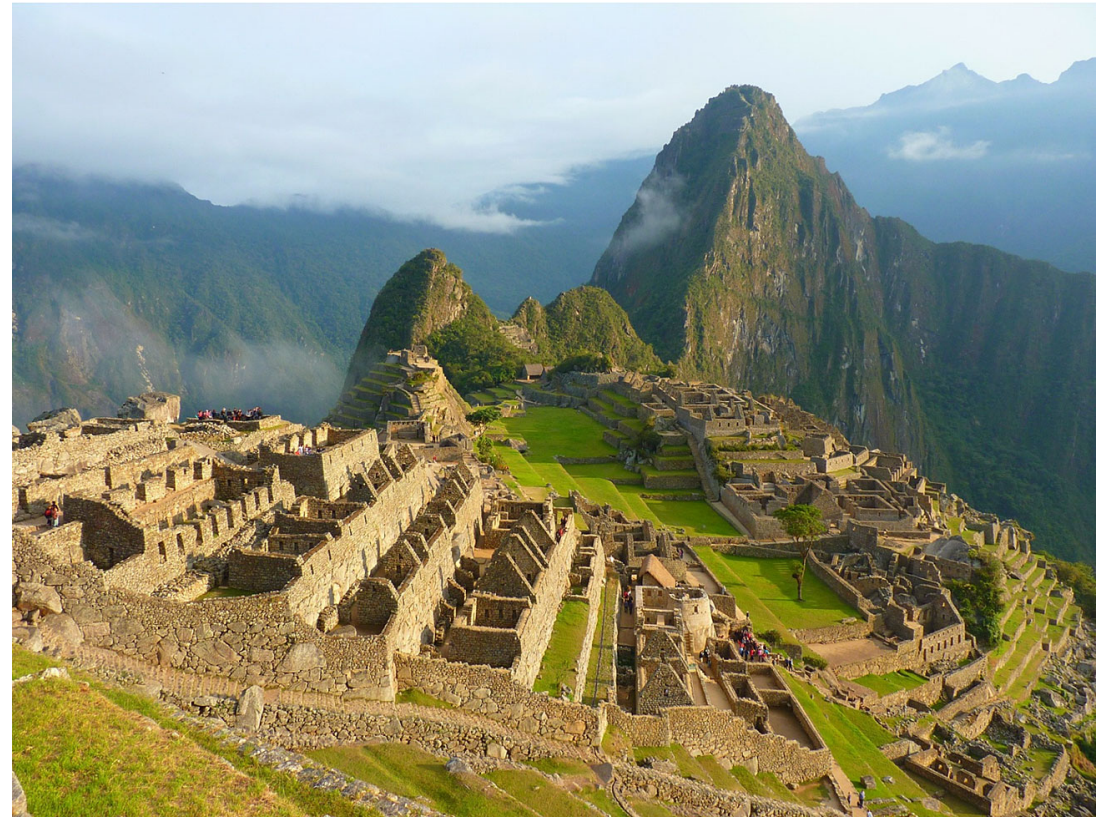

of life and destiny of each individual. And in a time marked by magic, prophecies, and religion, they consumed these psychoactive substances in group ceremonies to achieve intoxication to embark on their shamanic voyages to communicate with spirits to acquire knowledge about plants, to diagnose epidemics, to ensure good harvests, to predict rain seasons, to know the outcome of wars and also to predict sickness and health, life expectancy, future diseases, and the fate of newborns. Ritual enemas were also used to induce trance-like states. All of this was accompanied by ritual songs and dances performed to the beat of drums and contained within a religious circle symbolizing death and resurrection. These substances were also administered to their warriors so they could experience a trance like state that would allow them to fight without feeling fear, thirst, or hunger.

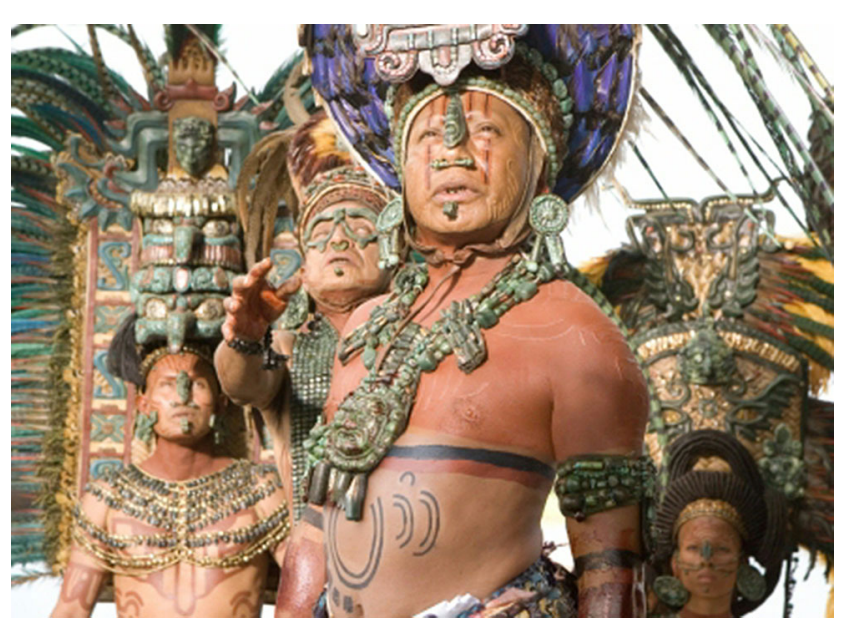

Fig. 7 Shaman worshipping Sun and Gods. Courtesy of "Apocalypto" Director Mel Gibson, Copyright: @Icon
Given that the different ethnic groups of the time lived in a constant state of war, of full body-to-body combat which resulted in numerous injuries, deaths, and executions, this provided hands on knowledge of the human body, of anatomy. The acquired knowledge began to be reflected in their surgical procedures in the treatment of war injuries, the decapitation of prisoners, and in the development of war headgear to protect the main part of the body: the brain and to strike adversaries with more accurate precision (Fig. 8a, b).

Human sacrifices, considered a debt paid to the Gods in return for their favors in winning battles, fertility of families and animals, ensuring rain, among other things, also greatly contributed to the knowledge of the human body, especially of the nervous system and to a superficial knowledge of neurological disorders. Victims were beheaded lying down and an obsidian or a quartz knife was used. (Fig. 9) Priests would make the initial incision, then, with a quick, masterful move, the heart was removed and given as the ultimate offering to the Gods. (Fig. 10) And finally, the poor individual's head was cut off.

These heads had three main purposes: offered to the temples, displayed in a trophy style gallery of skulls, or used to make ornamental masks. How these masks were made showed technical precision that included scrapings, abrasions, and bone separation, gem incrustations in orbital lobes, and obsidian, quartz or flintstone blades in the nasal and oral cavities. These masks represented a bond between life and death (Fig. $11 \mathrm{a}, \mathrm{b}, \mathrm{c}, \mathrm{d}$ ).

The Indians considered that the body consisted of three main areas:

1. The head (cuaitl) contained the conscience, reason, and the tonali, the individual's shadow that could be lost in 
Fig. 8 a Warrior using his maza or clava against the cranium of his opponent. Courtesy: Professor

Doctor Fernando Rueda Franco. b

Warrior with a large tumi used to

decapitate enemy. Courtesy:

Museo del Oro, Lima, Perú
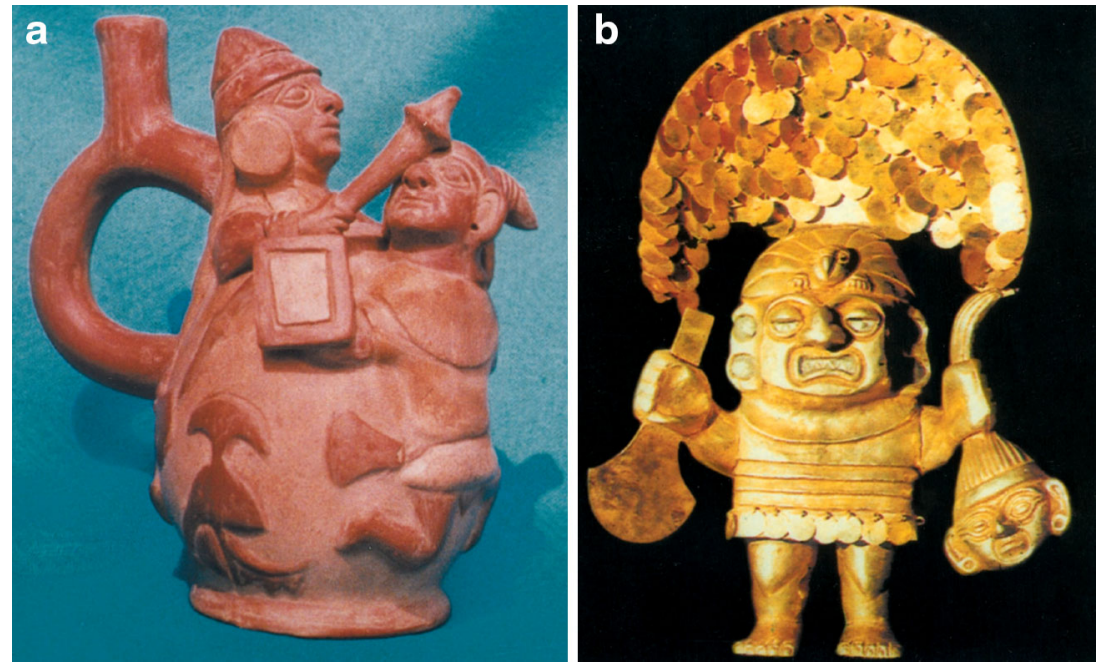

dreams, repeated coitus, drunkenness, and it could be recovered by consuming cocoa, chicha, chiles or using a redwood charm.

2. The heart (yollotl) contained the individual's emotional processes, vital functions, and rational thought.

3. The liver (ihiyotl), encompassing the body's lower part, contained the emotions originating from the underworld.

As in all war oriented cultures, there was a clear intent to rescue and cure young injured warriors. Pre-Columbian doctors were extremely interested in head injuries as is evidenced in the remains found in Mayan archeological sites. These remains show wounds sutured with human hairs, fracture reductions, and dental prostheses made of turquoise or jade. For example, Aztec doctors knew that severe head injuries and injuries to the superior part of the spinal cord were lethal and if the injured survived, they became known as "men with crippled hands" and were not treated due to their poor prognosis.

Various battle weapons were used at the time, as were helmets, protective warrior headgear used to protect the brain, due to their extensive knowledge of the severity of head traumas. These are axes, clubs, spikes, spears, slings, bolas, etc. An image of an Incan warrior wearing his uniform: sandals, shield, breastplate, and a protective helmet to prevent head trauma with a spear in his right hand (Fig. 8a, b).

Numerous carved sculptures from this time period have been found showing post-traumatic facial paralysis, spins bifida with kyphosis, orbital tumor, facial paralysis and Krauze syndrome, among other malformations (Fig. 12a-e).
Fig. 9 Image of Shaman offering heart to the Gods. Courtesy of "Apocalypto" Director Mel Gibson, Copyright: @Icon

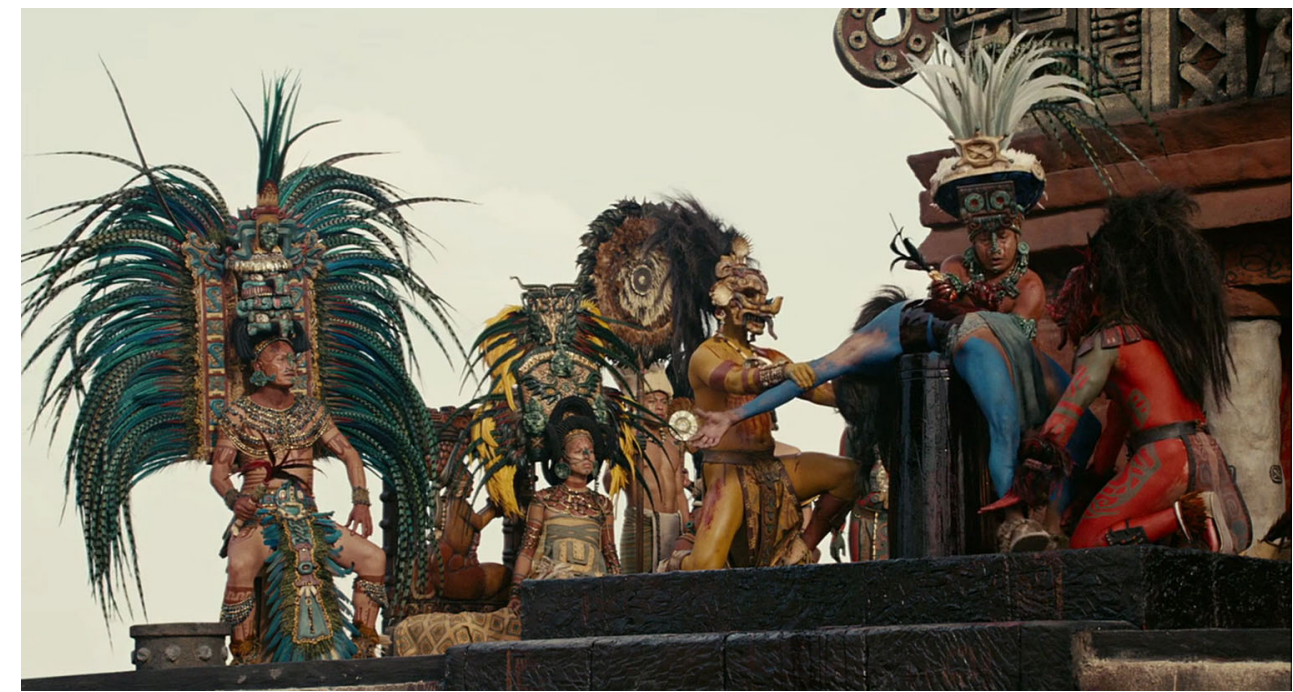




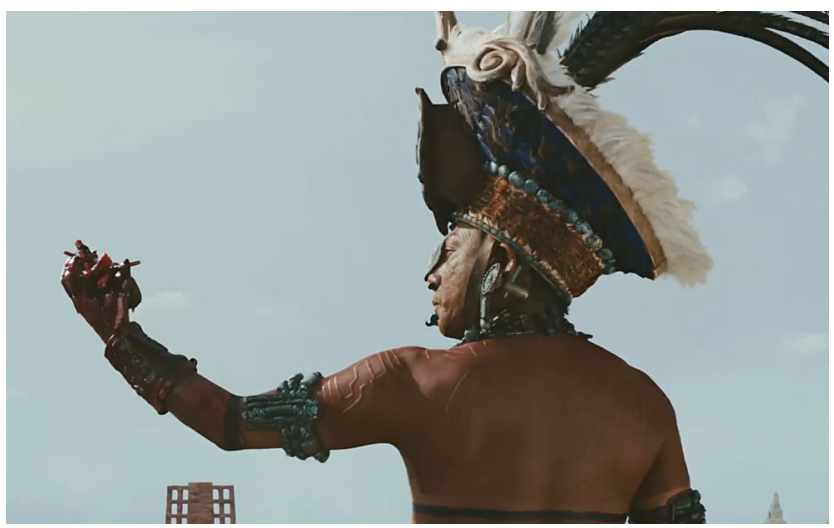

Fig. 10 Image of human sacrificial ceremony. Courtesy of "Apocalypto" Director Mel Gibson, Copyright: OIcon

There were three principal neurosurgical practices at that time:

\section{Cranial trephination \\ 2. Intentional cranial deformation \\ 3. Head shrinking}

The suggested reasons for trephination surgeries in ancient Peru are numerous: for trauma, fractures, diseases of the cranium, epilepsy to release evil spirits, headaches, mental disease, and some rituals.

In the National Museum of Anthropology and Archeology in Peru, there are 15,000 skulls and sitting mummies that have been preserved and recovered from pre-Colombian civilizations.

If the patient was conscious, the anesthesia applied was intoxication with alcohol using "chicha", a beverage derived from fermented maize, accompanied by chewing coca leaves and by techniques of hypnosis or suggestion. The principal instrument used in craniotomies was the ceremonial tumi knife in bronze, but bone elevators, dissectors, and needles were also used.
Four different trepanation techniques of the time have also been discovered:

1. Scraping or abrasive techniques done with obsidian, a volcanic glass sharpened and hoisted on a wooden handle to serve as a scalpel blade (Fig. 13a);

2. A second technique was to carve out a circular cone like orifice (Fig. 13b)

3. The third was incising linear grooves to make a square shaped hole in the skull. In this image, surely used to treat the large fracture this patient presented. (Fig. 13c)

4. In children, supra-inion trepanation was practiced, scraping the external table above the inion without perforating the inner table. This was considered a baptism ritual and a prophylactic procedure to protect patients from future problems such as headaches.

The more advanced cultures practiced gold cranioplasty. They possessed such an advanced knowledge of anatomy that they never included the middle line in craniotomies because they knew that this would produce massive hemorrhaging and they never perforated the meninges because they knew that if they did, inevitably infection and death would follow.

The patients' post-surgery survival prognosis was calculated based on the presence of osteoporosis in craniotomies' borders. When the marks done by the surgical instruments could be perfectly identified, this demonstrated that survival was minimal. An osteoporotic halo with a moth-eaten appearance meant survival of 1 to 3 weeks. An important presence of osteoporosis associated with an inflammatory reaction and necrosis, suggests survival of 4 to 7 weeks. Evidence of osseous bridges formed between the edges, suggests survival of 8 to 12 weeks. And fully healed borders, where both cortical bones have joined and the diploe has disappeared, the patient survived indefinitely (Fig. 14a-e).

The intentional deformation of a newborn infant's skull was common in the Mesoamerican cultures. This practice

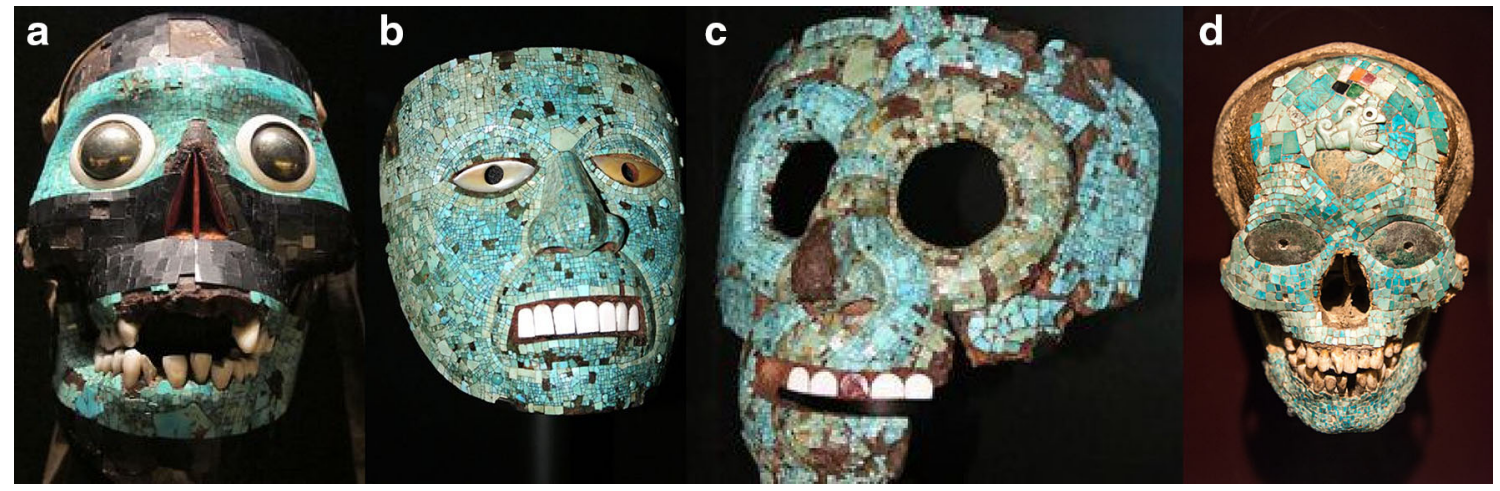

Fig. 11 Variety of ornamental masks. a-c) Courtesy of www.britishmuseum.org 

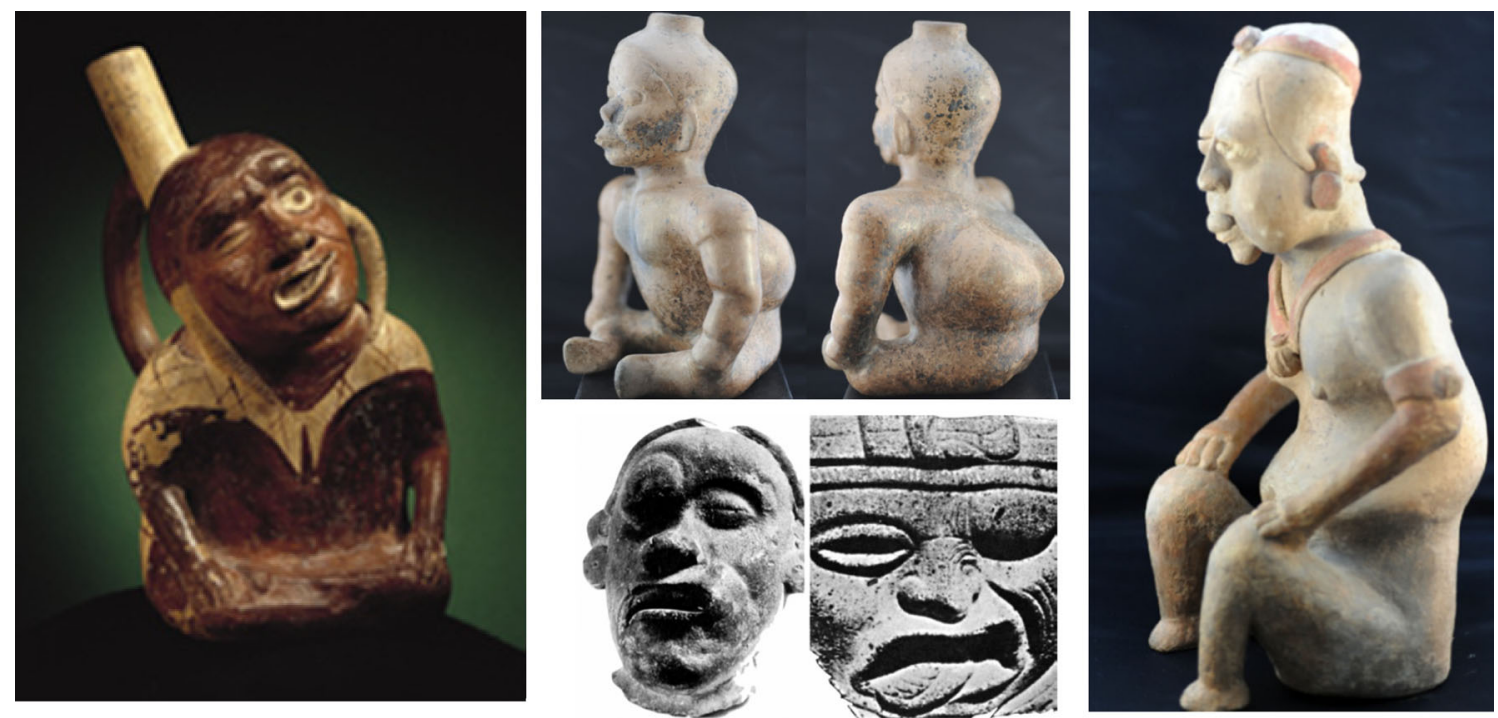

Fig. 12 a-e) Sculptures depicting deformities and syndromes. Courtesy: Private Collection of James T. Goodrich

Fig. 13 a-c) Different

trepanation techniques. Courtesy: Fernández Díaz-Formentí, J.M

Fig. 14 a-e) A patients' postsurgery survival prognosis based on the presence of osteoporosis in craniotomies' borders. Couresty: Fernández Díaz-Formentí, J.M
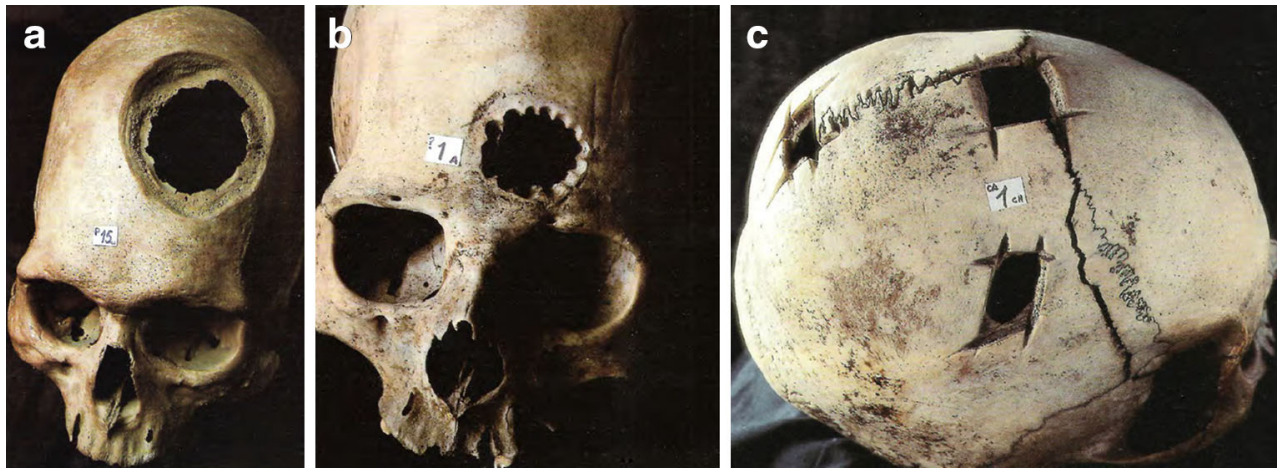

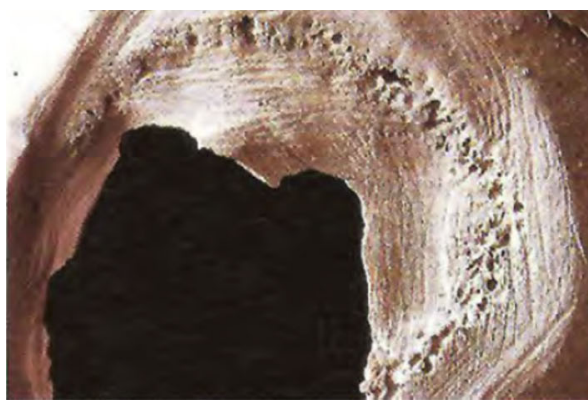

a Less than a week

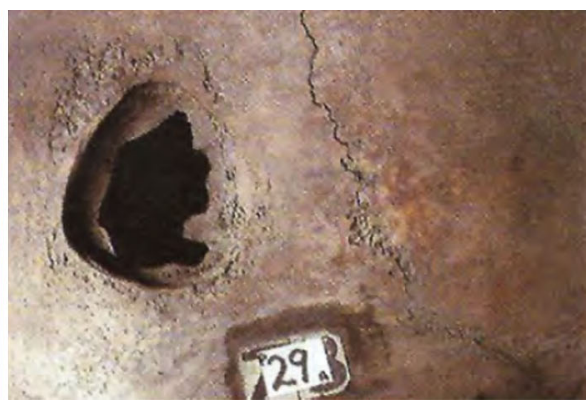

b 1-3 weeks

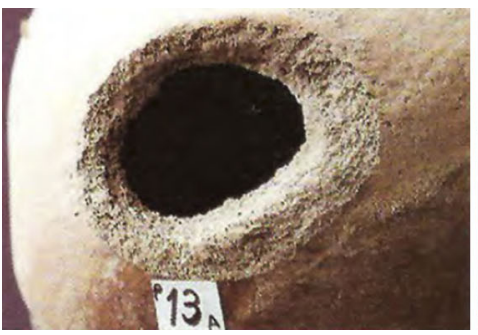

c 4-7 weeks

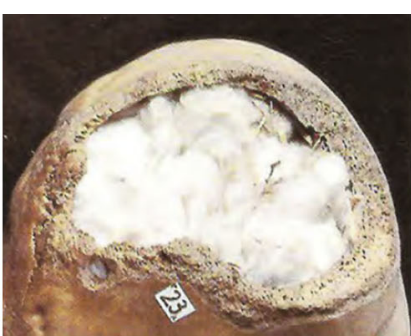

d 8-12 weeks

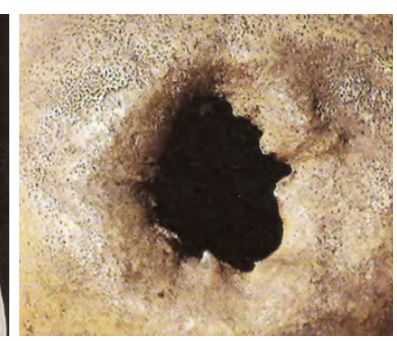

e More than 12 weeks 
Fig. 15 a) and b) Cranial manipulation techniques
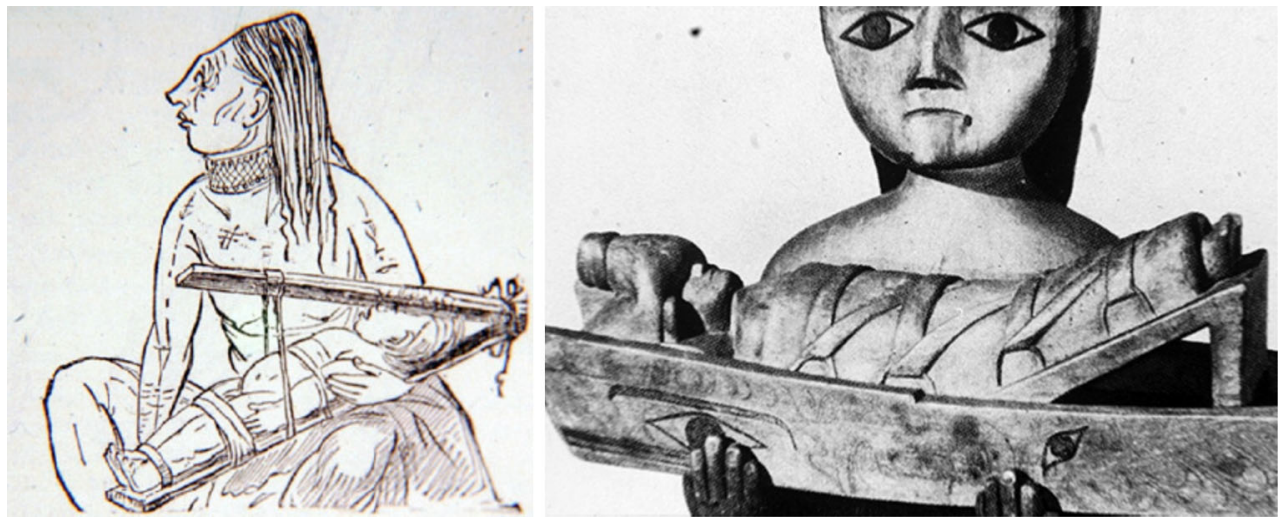

was limited to the upper classes and nobility, and its practice prohibited in slaves and the lower classes. This practice allowed for tribal identification since the tribes of each region used a different head shape. Several techniques were used to bind and shape the head, including the use of cradles and other boards, cloth bindings applied to the skull. (Fig. 15a, b) Cranial deformation was greatly opposed by the Catholic Church because it was considered a pagan practice but today, helmets are used to remodel positional plagiocephaly (Fig. 16).

The third neurosurgical procedure was the shrinking of human heads. This practice was common among the JivaroShuar tribe living in the upper Amazon basin of southeastern Ecuador and Peru. They were bloodthirsty warriors that lived in small groups of 10 to 12 in the same household where the eldest was the leader. The households went to war because the eldest member believed that the death of a member was due to the evil sorcery performed by another other household. The identity of this enemy was determined by the Shaman under the influence of hallucinogens. The warriors were accompanied into war by all members of the household, including wives and children. Once a household was defeated, all of its members were killed and decapitated, their heads later shrunk. The children were killed and abandoned without decapitation. After 2 days of rituals, the triumphant household proceeded to shrink the heads (called tsantsa) (Fig. 17).

First, they removed the victims' scalp, starting with an incision at the base of the ear to the base of the neck. They removed the skin of the head and face, and with sharpened wooden pins removed the remaining cartilages of the nose and ears and enucleated the victims' eyes. The skull itself was discarded. Then in a ceramic pot with boiling water, the

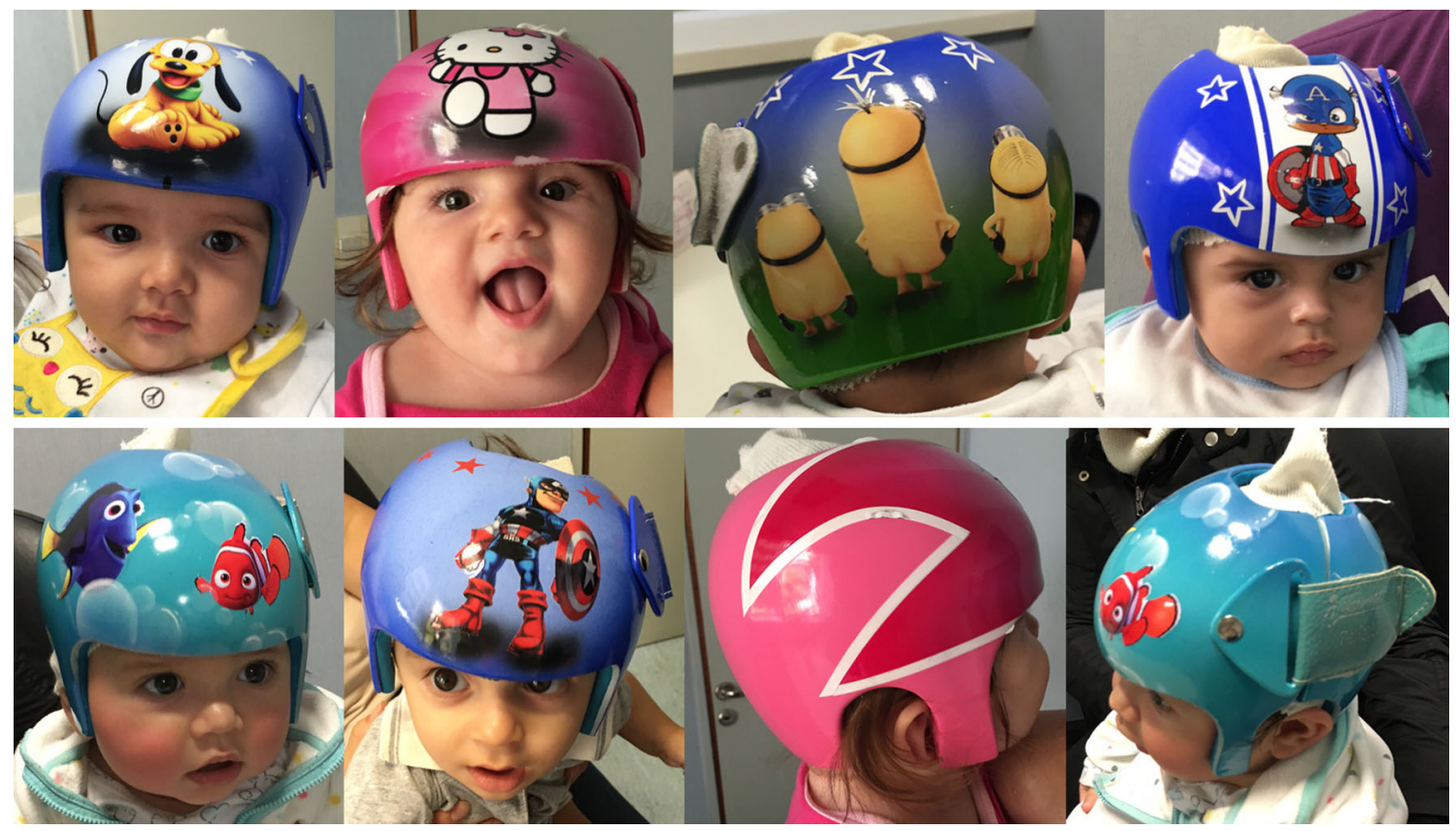

Fig. 16 Modern day cranial manipulation to remodel positional plagiocephaly. Courtesy: Private Collection of Graciela Zúccaro 


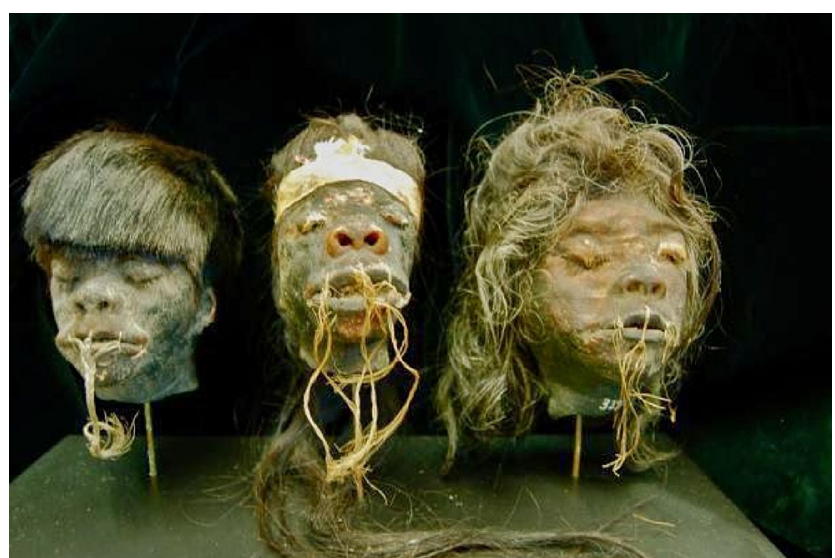

Fig. 17 Shrunken heads of the Jivaro-Shuar

victims' skin was grabbed by the hair and submerged three times. Then the skin was dried. Once dry, the hair was tied on the scalp, the mouth was closed with darts and the eyelids were sutured. This ceremony lasted several days, accompanied by ritual songs and dances until the warriors returned triumphant to their own household. These shrunken heads were displayed as trophies for one year, after which they were either discarded or given to the household's children as baubles.

In conclusion, medicine constitutes one of the most important legacies from the pre-Colombian-Mesoamerican cultures and has had an impact in European culture since the sixteenth century. As a result, the fusion of the European origins of medicine with these New World cultures, gave way to a new form of syncretism of medicine and therapeutics in the institutions later founded in New Spain. Several contributions to medical practice have surely emerged from these historical decapitations, trephinations, head shrinking techniques, and human sacrifices. Based on the existence of a specialized caste of doctors and shamans, we can hypothesize about the level of expertise they might have achieved through the continuous practice of these early neurosurgical procedures.

Acknowledgements The author would like to thank María Amelia Gamba for her investigation, data collection and translation.

\section{Compliance with ethical standards}

Conflict of interest The author states that there is no conflict of interest. 